\title{
The extracellular matrix of the lung and airway responsiveness in asthma
}

\author{
F.G. Salerno1,2, M.P. Foschino Barbaro1, O. Toungoussova2, \\ E. Carpagnano1, P. Guido2, A. Spanevello1,2
}

\begin{abstract}
The extracellular matrix of the lung and airway responsiveness in asthma. F.G. Salerno, M.P. Foschino Barbaro, O. Toungoussova, E. Carpagnano, P. Guido, A. Spanevello.

The extracellular matrix is the main determinant of the structure and of mechanical behaviour of the lung. The extracellular matrix is also responsible for the mechanical interdependence between airway and parenchyma due to the alveolar attachments to the airways. Asthma is characterized by bronchial hyperresponsiveness, airway remodelling and inflammation, and an altered extracellular matrix may play a role in all these functional
\end{abstract}

and structural abnormalities. The excessive airway narrowing observed in asthma may be related to the altered viscoelastic properties of lung parenchyma and airway wall, determining a decrease in the mechanical load opposing the airways' smooth muscle contraction. Indeed, an altered extracellular matrix deposition in asthma in humans, has been demonstrated. In addition, in the asthmatic lung, the matrix seems to contribute to airway inflammation, airway remodelling, and to those alterations of the smooth muscle function of the airway and morphology typical of asthma.

Monaldi Arch Chest Dis 2009; 71: 1, 27-30.

Keywords: Airway smooth muscle, Airway remodelling, Proteoglycan, Decorin.

${ }^{1}$ Cattedra di Malattie dell' Apparato Respiratorio, Università degli Studi di Foggia;

2 Divisione di Pneumologia, Fondazione Salvatore Maugeri, 70020 Cassano Murge (Bari), Italy.

Correspondence: Dr. Francesco G. Salerno, Fondazione Salvatore Maugeri, Via per Mercadante Km 2, 70020 Cassano Murge (BA), Italy; e-mail: francesco.salerno@fsm.it

The extracellular matrix and the mechanical properties of the lung

The extracellular matrix is the main determinant of the structure, as well as the mechanical properties of both the lung parenchyma and the airway wall [1]. The extracellular matrix comprises the fibre (elastic and collagen fibres) and the interfibre compartment. The interfibre compartment includes mainly two types of glycosaminoglycans (GAGs): nonsulphated GAGs (hyaluronic acid) and sulphated GAGs (heparan sulphate and heparin, chondroitin sulphate, dermatan sulphate, and keratan sulphate). GAGs are usually covalently attached to a protein core, forming proteoglycans. In the lungs, GAGs are located in the interstitium, in the sub-epithelial tissue and bronchial walls. Functions of GAGs include tissue hydration, maintenance of structure, modulation of the inflammatory response, and regulation of tissue repair and tissue remodelling $[2,3]$. The extracellular matrix is the main determinant of the elastic properties of lung parenchyma and airways, as tissue compliance is governed mainly by the threedimensional arrangement of collagen and elastin. When isolated lung tissue is exposed in vitro to elastase, an enzyme that digests elastin and collagen disrupting the three-dimensional network of fibres that compose the architecture of the tissue, lung compliance increases [4]. The extracellular matrix is also responsible for a large part of the lung tissue hysteretic properties, and of the energy dissipation occurring during breathing accounted for by lung tissue resistance [5].

Bronchial hyperresponsiveness is defined by the excessive airway narrowing that follows stimulation with an airway smooth muscle agonist. Both under normal conditions and in asthmatic patients, the degree of airway narrowing for a given airway smooth muscle challenge is determined by the balance between the shortening capacity of airway smooth muscle and the mechanical load opposing it. The mechanical load includes the stress related to the deformation of the airway wall, and the stress related to the elastic recoil of the surrounding parenchyma [6]. In fact, the lung parenchyma, under normal conditions exerts a dilating effect on the intraparenchymal airways through the airway-parenchymal attachments [7]. Another source of mechanical load is related to the radial expansion of the intercellular tissue network as the muscle changes its shape reaching very short lengths [8]. Breathing is a dynamic process. Airways operate under dynamic conditions and the mechanical relationship between airway smooth muscle and its external environment is dynamic. Indeed, both muscle length and muscle force are regulated dynamically with the interaction to the time dependent mechanical load [9]. The quality and quantity of the extracellular matrix determines 
the largest part of the mechanical load opposing airway smooth muscle shortening. The extracellular matrix may, therefore, have an impact on airway smooth muscle function under static and even more under dynamic conditions.

\section{Extracellular matrix and asthma}

The extracellular matrix is the main determinant of the normal structure of lung parenchyma and airway wall, and it is involved in the many structural abnormalities seen in the asthmatic lung. The structure of the lung parenchyma and airway wall impact on the mechanical impedance opposing airway smooth muscle shortening. Bronchial hyperresponsiveness may be a function of the altered mechanical impedance of lung parenchyma and airway wall to airway smooth muscle contraction. Breathing is a dynamic event, and under dynamic conditions, a reduced impedance may lead to excessive airway smooth muscle shortening and to increased velocity of smooth muscle shortening. Indeed, it has been demonstrated that it is a shortening velocity rather than force generation per unit of muscle mass that is related to bronchial hyperresponsivenss [10]. Another mechanism, possibly relating extracellular matrix and asthma, is the ability of lung volume excursions to relax airway smooth muscle and decrease lung elastance [5].

Alterations in the relative proportion of the matrix molecular components are described in asthmatic lungs. Biopsies of asthmatic airways show a thickening of the basement membrane and increased collagen deposition. Recently, an increase in proteoglycans in asthmatic airways has been demonstrated in addition to collagen and fibronectin deposition $[11,12]$.

Chronic airway inflammation and airway remodelling are defining features of bronchial asthma [13], and several studies have shown that alterations in extracellular matrix deposition contribute to this process $[11,12,14]$. Huang et al [11] have observed an increased proteoglycan deposition in immunostained endobronchial biopsies of asthmatics as compared to controls. A significant correlation between the degree of immunoreactivity and the degree of airway hyperresponsiveness was also found.

The interaction between extracellular matrix and airway smooth muscle is complex. It has been shown that extracellular matrix proteins might modify the airway smooth muscle function and morphology in a way that might potentially facilitate asthma [15]. Different matrix proteins influence airway smooth muscle cells survival and proliferation. Hirst et al [16] have demonstrated that collagen and fibronectin affected airway smooth muscle proliferation. In addition, a greater expression of contractile proteins, such as $\alpha$-actin or smooth muscle heavy chain was observed when cells were grown on laminin. D'antoni et al [17] have studied the effect of decorin and biglycan on human airway smooth muscle cell proliferation and apoptosis. A significant decrease in smooth muscle cell number was observed with cells seeded on decorin. Slats et al [18] examined, in bronchial biopsies of asthmatic patients, the expression of several contractile and structural proteins of the smooth muscle cells and of the extracellular matrix. When the expression of these proteins was related to lung function, airway responsiveness to methacholine was found to be inversely related to $\alpha$ smooth muscle actin, desmin and elastin, whereas $\mathrm{FEV}_{1}$ was positively correlated to desmin and calponin. This data suggests a relationship between airway function and the expression of contractile and structural proteins of the airway smooth muscle and of the extracellular matrix.

The airway smooth muscle cell is able to synthetise and secrete various matrix proteins, and it has been shown that this ability is enhanced in smooth muscle cells of asthmatic patients. Johnson et al [19] demonstrated that matrix proteins secreted by asthmatic airway smooth muscle cells increased smooth muscle proliferation. Finally, the extracellular matrix proteins secreted by the asthmatic airway smooth muscle are able to enhance the release of inflammatory cytokines, therefore, aggravating tissue inflammation.

There are differences in the extracellular matrix of asthmatic lungs depending on the functional severity of the disease. A recent study by Pini et al [12] revealed that patients with moderate asthma had greater amount of biglycan and lumican in the airway smooth muscle layer than severe asthmatics. The authors suggested that differences in the deposition of proteoglycans within the airway smooth muscle layer may impact on the physiology of bronchoconstriction in different group of asthmatic patients. It has also been demonstrated that proteoglycans deposition was different in fatal asthma versus non fatal asthma, with again possible implications on bronchial pathophyisiology [20]. Araujo et al [21] compared subjects with fatal asthma with subjects with non fatal asthma and with non asthmatic controls. The expression of collagen, fibronectin, versican, matrix metalloproteinases and tissue inhibitor of metalloproteinase was quantified within the airway smooth muscle. They found an altered matrix within the airway smooth muscle layer in fatal asthma with possible consequences for the mechanical and synthetic functions of airway smooth muscle. Further studied are needed in order to better establish the possible biomechanical and biological implications of the altered matrix components in asthma of different severity.

\section{Decorin and asthma}

Decorin, a leucine-rich proteoglycan, has important biological functions with a potential role in asthma pathophysiology $[12,22]$. Decorin has been demonstrated to affect collagen fibrils formation and organization in the matrix, and it might be involved in the process of airway remodelling [23]. Decorin has also the capability of binding TGF-beta, a cytokine involved in the process of airway inflammation and remodelling [24]. Decorin, as well as other proteoglycans, affects al- 


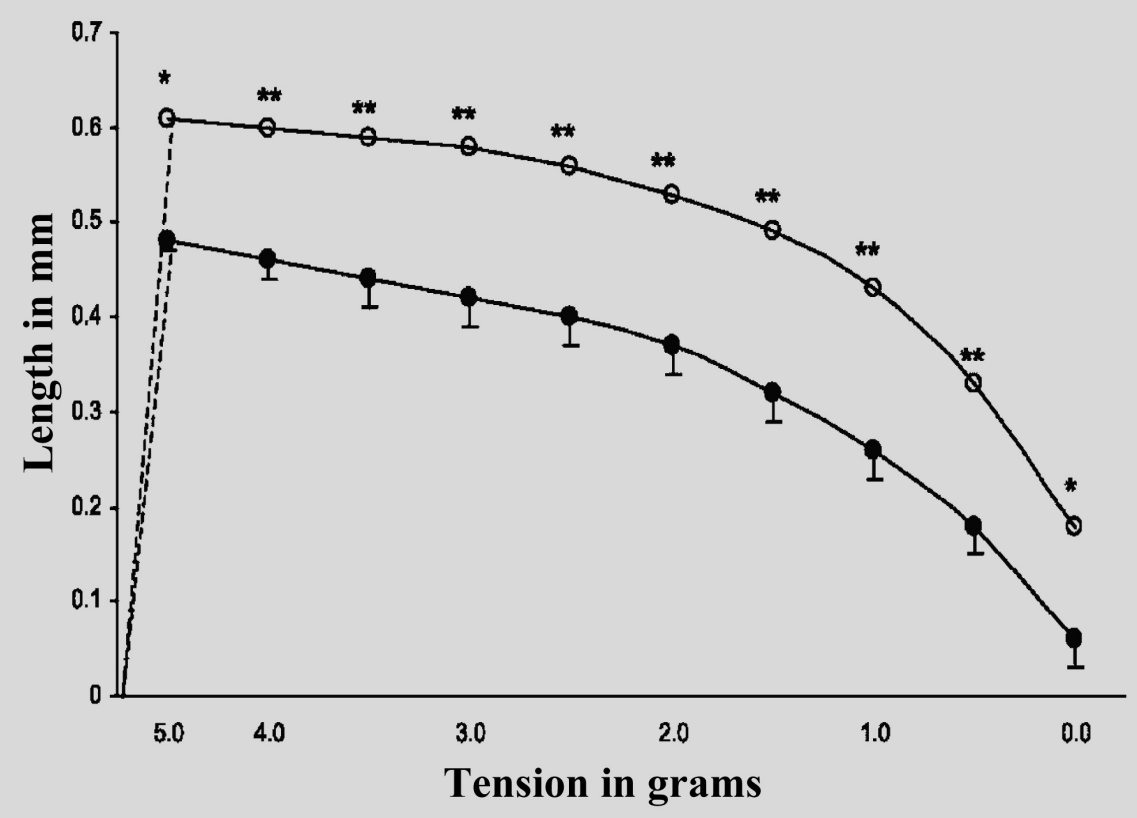

Fig. 1. - Length vs. tension curves during relaxation in isolated tracheal rings from Dcn+/+ (filled symbol) and Dcn-/- (open symbol) mice. $* P 0.01$ vs. Dcn $+/+$. $* * P 0.001$ vs. $D c n+/+$ (modified from reference 22$)$.

so lung fibroblast morphology and migration, cell proliferation and apoptosis [25]. Fust et al. [26] have shown, using an animal model (mice) where the decorin gene was abrogated, that lung mechanics in the absence of decorin were altered. Specifically, mice lacking decorin decreased airway resistance and increased lung compliance. Immunohistochemistry analysis has shown that decorin was localized mainly around the airway and vessel wall [22]. Indeed, not only parenchyma, but also airways display altered elastic properties in decorin deficient animals [22] (fig. 1). In so far as decorin is distributed peribronchially, it may also affect the mechanical interdependence between airway and parenchyma. In other words, the abnormal quantity of decorin in the airways may affect the link between lung parenchyma and airway smooth muscle, resulting in an altered transmission of the tethering force. In addition, a more compliant airway may dilate more for the same amount of lung parenchymal tethering. Finally, the altered collagen morphology and spatial distribution induced by the lack of decorin, where fibrils are irregular and interwoven, may further contribute to the changes of parenchymal mechanics seen in vitro and in vivo $[22,26]$. Further work is needed in order to establish the real importance of decorin in the pathophysiology of human lung diseases.

\section{Conclusions}

The extracellular matrix is the main determinant of the structure, as well as of the mechanical properties of the lung. Several studies have shown that alterations in extracellular matrix deposition contributed to the airway inflammation and airway remodelling typical of asthma. The abnormal ma- trix composition, as is seen in asthma, may affect airway smooth muscle function and morphology. Taken together, these findings suggest that the altered extracellular matrix, described in asthmatic airways, may affect the mechanical properties of the lung, the mechanical impedance opposing airway smooth muscle contraction, and possibly airway smooth muscle contractility, contributing to the increased bronchial responsiveness to methacholine, characteristic of the disease. Further studies are necessary in order to establish the real importance of the extracellular matrix in the pathophysiology of asthma.

\section{References}

1. Cavalcante FS, Ito S, Brewer K, et al. Mechanical interactions between collagen and proteoglycans: implications for the stability of lung tissue. J Appl Physiol 2005; 98: 672-679.

2. Iozzo RV. Matrix proteoglycans: from molecular design to cellular function. Annu Rev Biochem 1998; 67: 609-652.

3. Iozzo RV. The family of the small leucine-rich proteoglycans: key regulators of matrix assembly and cellular growth. Crit Rev Biochem Mol Biol 1997; 32: 141-174.

4. Moretto A, Dallaire M, Romero P, Ludwig M. Effect of elastase on oscillation mechanics of lung parenchymal strips. J Appl Physiol 1994; 77:1623-1629.

5. Salerno FG, Fust A, Ludwig MS. Stretch-induced changes in constricted lung parenchymal strips: role of extracellular matrix. Eur Respir J 2004; 23: 193-198.

6. Macklem PT. A theoretical analysis of the effect of airway smooth muscle load on airway narrowing. Am J Respir Crit Care Med 1996; 153: 83-89.

7. Ding DJ, Martin JG, Macklem PT. Effects of lung volume on maximal methacholine-induced bronchoconstriction in normal humans. $J$ Appl Physiol 1987; 62: 1324-1330. 
8. Meiss RA. Influence of intercellular tissue connections on airway muscle mechanics. J Appl Physiol. 1999; 86: $5-15$.

9. An SS, Fredberg JJ. Biophysical basis for airway hyperresponsiveness. Can J Physiol Pharmacol 2007; 85: 700-714.

10. Antonissen LA, Mitchell RW, Kroeger EA, Kepron W, Tse KS, Stephens NL. Mechanical alterations of airway smooth muscle in a canine asthmatic model. J Appl Physiol. 1979; 46: 681-687.

11. Huang J, Olivenstein R, Taha R, Hamid Q, Ludwig MS. Enhanced proteoglycan deposition in the airway wall of atopic asthmatics. Am J Respir Crit Care Med 1999; 160: 725-729.

12. Pini L, Hamid Q, Shannon J, et al. Differences in proteoglycan deposition in the airways of moderate and severe asthmatics. Eur Respir J 2007; 29: 71-77.

13. Jeffery PK. Remodelling in asthma and chronic obstructive lung disease. Am J Respir Crit Care Med 2001; 164: S28-S38.

14. Pini L, Torregiani C, Martin JG, Hamid Q, Ludwig MS. Airway remodelling in allergen-challenged Brown Norway rats: distribution of proteoglycans. Am J Physiol Lung Cell Mol Physiol 2006; 290: L1052L1058.

15. Tran T, Halayko AJ. Extracellular matrix and airway smooth muscle interactions: a target for modulating airway wall remodelling and hyperresponsiveness. Can J Pharmacol 2007; 85 666-671.

16. Hirst SJ, Twort CH, Lee TH. Differential effects of extracellular matrix proteins on human airway smooth muscle cell proliferation and phenotype. Am J Respir Cell Mol Biol 2000; 23: 335-344.

17. D'Antoni ML, Torregiani C, Ferraro P, et al. Effects of decorin and biglycan on human airway smooth muscle cell proliferation and apoptosis. Am J Physiol Lung Cell Mol Physiol 2008; 294: L764-771.

18. Slats AM, Janssen K, van Schadewijk A, et al. Expression of smooth muscle and extracellular matrix proteins in relation to airway function in asthma. $J$ Allergy Clin Immunol 2008, 121: 1196-1202.

19. Johnson PR, Burgess JK, Underwood PA, et al. Extracellular matrix proteins modulate asthmatic airway smooth muscle cell proliferation via an autocrine mechanism. J allergy Clin Immunol 2004 113: 690-696.

20. de Medeiros Matsushita M, da Silva LF, dos Santos MA, et al. Airway proteoglycans are differentially altered in fatal asthma. $J$ Pathol 2005; 207: 102-110.

21. Araujo BB, Dolhnikoff M, Silva LF, et al. Extracellular matrix components and regulators in the airway smooth muscle in asthma. Eur Respir $J$ 2008; 32: 61-69.

22. Salerno FG, Pinelli V, Pini L, Tuma B, Iozzo RV, Ludwig MS. Effect of PEEP on induced constriction is enhanced in decorin-deficient mice. Am J Physiol Lung Cell Mol Physiol 2007; 293: L1111-L1117.

23. Danielson KG, Baribault H, Holmes DF, Graham H, Kadler KE, Iozzo RV. Targeted disruption of decorin leads to abnormal collagen fibril morphology and skin fragility. J Cell Biol 1997; 136: 729-743.

24. Redington AE, Roche WR, Holgate ST, Howarth PH. Co-localization of immunoreactive transforming growth factor-beta 1 and decorin in bronchial biopsies from asthmatic and normal subjects. J Pathol 1998; 186: 410-415.

25. Souza-Fernandes AB, Pelosi P, Rocco PRM. Bench-tobedside review: The role of glycosaminoglycans in respiratory disease. Critical Care 2006, 10: 237.

26. Fust A, LeBellego F, Iozzo RV, Roughley PJ, Ludwig MS. Alterations in lung mechanics in decorin-deficient mice. Am J Physiol Lung Cell Mol Physiol 2005; 288: L159-L166.

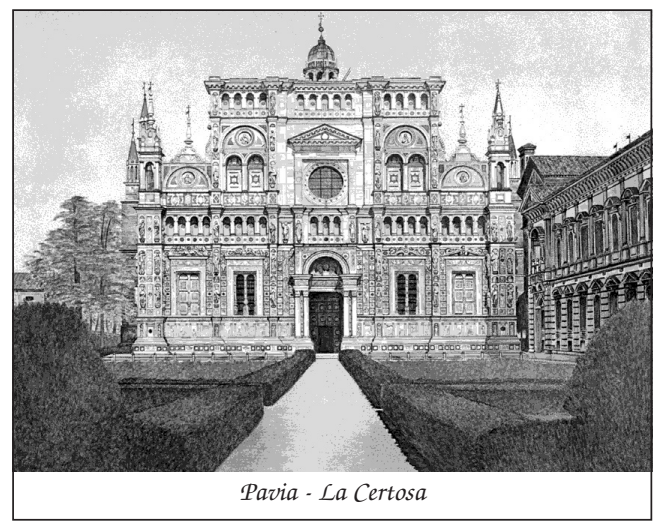

